\title{
A Melanin-like Nanoenzyme for Acute Lung Injury Therapy via Suppressing Oxidative and Endoplasmic Reticulum Stress Response
}

\author{
Xue-Fang Lou ${ }^{1,+}$, Chen Wang ${ }^{2,+}$, Ju-Cong Zhang ${ }^{2}$, Yong-Zhong Du ${ }^{2, *}$ and Xiao-Ling $\mathrm{Xu}^{3, *}$ \\ 1 School of Medicine, Zhejiang University City College, 51 Hu-Zhou Street, Hangzhou 310015, China; \\ louxf@zucc.edu.cn \\ 2 Institute of Pharmaceutics, College of Pharmaceutical Sciences, Zhejiang University, Hangzhou 310058, China \\ 3170104036@zju.edu.cn (C.W.); 3170104034@zju.edu.cn (J.-C.Z.) \\ 3 Shulan International Medical College, Zhejiang Shuren University, Hangzhou 310004, China \\ * Correspondence: duyongzhong@zju.edu.cn (Y.-Z.D.); ziyao1988@zju.edu.cn (X.-L.X.); \\ Tel.: +86-571-88208435 (Y.-Z.D.) \\ + These authors contributed equally to this work.
}

\section{check for}

updates

Citation: Lou, X.-F.; Wang, C.; Zhang, J.-C.; Du, Y.-Z.; Xu, X.-L. A Melanin-like Nanoenzyme for Acute Lung Injury Therapy via Suppressing Oxidative and Endoplasmic Reticulum Stress Response. Pharmaceutics 2021, 13, 1850. https://doi.org/10.3390/ pharmaceutics 13111850

Academic Editors: Anna Angela Barba and Patrick J. Sinko

Received: 18 September 2021

Accepted: 1 November 2021

Published: 3 November 2021

Publisher's Note: MDPI stays neutral with regard to jurisdictional claims in published maps and institutional affiliations.

Copyright: (c) 2021 by the authors. Licensee MDPI, Basel, Switzerland. This article is an open access article distributed under the terms and conditions of the Creative Commons Attribution (CC BY) license (https:// creativecommons.org/licenses/by/ $4.0 /)$.

\begin{abstract}
Nanoenzyme-mediated catalytic activity is emerging as a novel strategy for reactive oxygen species (ROS) scavenging in acute lung injury (ALI) treatment. However, one of the main hurdles for these metal-containing nanoenzymes is their potential toxicity and single therapeutic mechanism. Herein, we uncovered a melanin-like nanoparticles derived from the self-polymerization of 1,8dihydroxynaphthalene (PDH nanoparticles), showing a significant anti-inflammation therapeutic effect on ALI mice. The prepared PDH nanoparticles rich in phenol groups could not only act as radical scavengers to alleviate oxidative stress but could also chelate calcium overload to suppress the endoplasmic reticulum stress response. As revealed by the therapeutic effect in vivo, PDH nanoparticles significantly prohibited neutrophil infiltration and the secretion of proinflammatory cytokines (TNF- $\alpha$ and IL-6), thus improving the inflammatory cascade in the ALI model. Above all, our work provides an effective anti-inflammatory nanoplatform by using the inherent capability of melanin-like nanoenzymes, proposing the potential application prospects of these melanin-like nanoparticles for acute inflammation-induced injury treatment.
\end{abstract}

Keywords: melanin-like nanoenzyme; acute lung injury; endoplasmic reticulum stress; oxidative stress; 1,8-DHN polymerized nanoparticles

\section{Introduction}

Acute lung injury (ALI) is a critical illness threatening public health [1-3] that is characterized serious inflammatory cell infiltration, pulmonary edema, and the formation of a hyaline membrane and interstitial fibrosis. Despite advances in pharmacotherapies and supportive care for ALI treatment, mortality and morbidity still remain unacceptably high $(30-40 \%)[4,5]$. The main reason for this could be attributed to the complex pathophysiological conditions based on the heterogeneity of etiological agents. Furthermore, the inflammatory cascade is quickly activated, resulting in rapid deterioration and possibly higher fatality. Thus, there is an urgent need to develop a more available therapeutic approach with multiple mechanisms for ALI treatment.

A variety of signaling pathways in pulmonary microvascular endothelial cells participate in the barrier permeability of ALI, including the increased intracellular calcium and reactive oxygen species (ROS) [6,7]. These two factors are regarded as key signaling events in the pathogenesis of ALI. Recently, researchers have pointed out that the expression of GRP78 and CHOP is upregulated in ALI models [8,9]. indicating that calcium overload-induced endoplasmic reticulum stress is involved in lung inflammation [10,11]. Furthermore, oxidative stress is often accompanied by abnormal increases in cytosolic 
calcium during endoplasmic reticulum stress in vivo [12-14]. It is presumed that both calcium overload and intracellular ROS generation can lead to mitochondrial dysfunction and then inflammatory cascade. Therefore, therapeutic interventions aiming to improve endoplasmic reticulum stress and oxidative stress may be warranted for the treatment of ALI.

The nanoenzyme is a type of nanomaterial with enzyme-like catalytic activity that has been developed in recent years, and it offers a new way of alleviating oxidative stress [15,16]. Since the first report of peroxidase-like activity of $\mathrm{Fe}_{3} \mathrm{O}_{4}$ nanoparticles in 2007 [17], significant progress has been made in the application of nanozymes for disease treatment. As most nanozymes are obtained by a metal or metal oxide, and their in vivo applications have been restricted due to long-term biosafety. Thus, researchers have made several efforts to develop metal-free nanozymes with catalytic activity. As a result, melanin-like nanoenzymes have begun receiving considerable research attention. Polydopamine, a type of melanin-like nanoenzyme derived from the self-polymerization of dopamine $[18,19]$, was able to exhibit excellent ROS-scavenging ability due to its phenolic structure [20], offering a prospective effective treatment due to the amelioration of oxidative damage. Zhao et al. [21] developed bare PDA nanoparticles as an anti-inflammatory nano-drug for the treatment of ALI. The results demonstrated that the prepared PDA nanoparticles could significantly diminish ROS generation, decrease cytokine secretion, inhibit neutrophil infiltration, and improve lung tissue damage. Inspired by PDA, Zhou et al. [22] synthesized another melanin-like nanoparticle via the oxidative oligomerization of 1,8-dihydroxynaphthalene (1,8-DHN). The obtained nanoparticle could be taken up by neonatal human epidermal keratinocytes and could protect them from UV exposure by quenching ROS. However, to the best of our knowledge, the application of 1,8-DHN-based allomelanin nanoparticles as an antiinflammatory agent to treat ALI has not yet been investigated. In addition, their ability to chelate calcium overload has not yet been explored.

In this work, bare 1,8-DHN-based allomelanin nanoparticles were prepared as antiinflammatory nanoenzymes for ALI therapy. The preparation procedure for these melaninlike nanoenzymes was first optimized by adjusting the concentration of the oxidant, the stirring speed, and the water-oil ratio. Then, the obtained nanoparticles were utilized to investigate their capability to scavenge ROS and chelate calcium overload in vitro. The cellular internalization mechanism was further evaluated by adding different endocytosis inhibitors. The cytoplasmic levels of the ROS and free calcium were then imaged by a fluorescent probe. Afterwards, the biodistribution of indocyanine green-labeled allomelanin nanoparticles was conducted in ALI mice and normal mice. Finally, the pharmacodynamic evaluation was performed after the treatment of 1,8-DHN-based allomelanin nanoparticles for $48 \mathrm{~h}$. Our design provides an effective anti-inflammatory nanoplatform by using the inherent capability of melanin-like nanoenzymes, suggesting the potential application prospect of these melanin-like nanoparticles as an anti-inflammatory nanomedicine.

\section{Materials and Methods}

\subsection{Materials and Animals}

The compounds 1,8-dihydroxynaphthalene (1,8-DHN), 3-(4,5-dimethylthiazol-2-yl)2,5-diphenyltetrazolium bromide (MTT), and sodium periodate $\left(\mathrm{NaIO}_{4}\right)$ were obtained from Sigma Chemical Co. (St. Louis, MO, USA). Indocyanine green (ICG) was purchased from Dalian Meilun Biotechnology Co., Ltd. (Dalian, China). Other chemicals applied in this research were of analytical or chromatographic grades.

BALB/c mice (6-8 weeks, male, $20 \mathrm{~g}$ ) were provided by the Shanghai Silaike Laboratory Animal Limited Liability Company (Shanghai, China). They were given sufficient food and water during treatments. The animal experiments were conducted under the National Institutes of Health (NIH, Bethesda, MD, USA) guidelines for the care and use of laboratory animals in research. In addition, the surgical experiments were approved by the Committee for Animal Experiments of Zhejiang University (12033, 26 February 2018). 


\subsection{Synthesis of 1,8-DHN Polymerized Nanoparticles}

We dissolved $20 \mathrm{mg}$ of 1,8-DHN in $20 \mathrm{~mL}$ of acetonitrile (5\%). Then, different volumes of $\mathrm{NaIO}_{4}(30 \mu \mathrm{L}, 60 \mu \mathrm{L}, 80 \mu \mathrm{L}, 100 \mu \mathrm{L}$, and $120 \mu \mathrm{L})$ were added dropwise. After stirring at $400 \mathrm{rpm}$ for $4 \mathrm{~h}, 1,8$-DHN polymerized nanoparticles (PDH) were retrieved by centrifugation (11,000 rpm, $10 \mathrm{~min}$ ) and were washed with water five times.

We dissolved $20 \mathrm{mg}$ of 1,8-DHN in $20 \mathrm{~mL}$ of acetonitrile with different concentrations (5\%, $10 \%, 20 \%, 50 \%$, and $70 \%$ ). Then, $100 \mu \mathrm{L}$ of $\mathrm{NaIO}_{4}$ was added dropwise. After stirring at $400 \mathrm{rpm}$ for $4 \mathrm{~h}, \mathrm{PDH}$ nanoparticles were obtained by centrifugation (11,000 rpm, $10 \mathrm{~min})$.

We dissolved $20 \mathrm{mg}$ of 1,8-DHN in $20 \mathrm{~mL}$ of acetonitrile (5\%). Then, $100 \mu \mathrm{L}$ of $\mathrm{NaIO}_{4}$ was added dropwise. After stirring at different speeds $(200 \mathrm{rpm}, 400 \mathrm{rpm}, 600 \mathrm{rpm}, 800 \mathrm{rpm}$, and $1000 \mathrm{rpm})$ for $4 \mathrm{~h}, \mathrm{PDH}$ nanoparticles were obtained by centrifugation $(11,000 \mathrm{rpm}$, $10 \mathrm{~min})$.

\subsection{Characterization of PDH Nanoparticles}

The size distribution and zeta potential of PDH nanoparticles on different days (day 1, $3,8,10,15$, and 18) were measured by dynamic light scattering (DLS, Zetasizer, Malvern Co., Malvern, UK) after their fabrication. The morphologies of the PDH nanoparticles were observed by transmission electron microscopy (TEM, JEOL JEM-1230, Tokyo, Japan).

The hemolysis assay was performed according to a previous study [23]. Red blood cells (RBCs) were harvested from rat blood after centrifugation ( $1500 \mathrm{rpm}, 15 \mathrm{~min}$ ) and were then diluted to a $2 \%$ suspension with saline. Afterwards, $0.5 \mathrm{~mL}$ of the RBC suspension was mixed with (1) $0.5 \mathrm{~mL}$ of saline as a negative control, (2) $0.5 \mathrm{~mL}$ of pure water as a positive control, and (3) $0.5 \mathrm{~mL}$ of PDH nanoparticles. In addition, $0.5 \mathrm{~mL}$ of PDH nanoparticles $(1 \mathrm{mg} / \mathrm{mL})$ mixed with saline served as a sample control. These samples were vortexed and maintained at room temperature for $3 \mathrm{~h}$. In addition to the sample control, other samples were centrifuged at $8000 \mathrm{rpm}$ for $5 \mathrm{~min}$. The hemolysis images were recorded. The absorbance $(A)$ of the supernatants at $541 \mathrm{~nm}$ was determined by a M5 full band multifunctional microplate reader (SynergyMx M5, Molecular Devices, San Francisco, CA, USA). The percent hemolysis of the RBCs was calculated as follows:

$$
\text { Percent hemolysis }(\%)=\frac{A_{\text {sample }}-A_{\text {negative }}}{A_{\text {positive }}-A_{\text {negative }}} \times 100 \%
$$

\subsection{Ability to Scavenge ROS}

Dichlorodihydrofluorescein (DCFH) can be rapidly oxidized to the strong fluorescent product $2^{\prime}, 7^{\prime}$-dichlorofluorescein (DCF) and is usually applied to react with ROS. Thus, DCFH $(5 \mu \mathrm{M}$, prepared according to a previous study [24]) and PDH nanoparticles $(1 \mathrm{mg} / \mathrm{mL})$ were mixed. Then, the absorbances of $\mathrm{PDH}, \mathrm{DCFH}, \mathrm{DCFH}+\mathrm{H}_{2} \mathrm{O}_{2}$, and DCFH $+\mathrm{H}_{2} \mathrm{O}_{2}+\mathrm{PDH}$ under different wavelength were recorded using an M5 full-band multifunctional microplate reader.

\subsection{Ability to Chelate Calcium Ions}

$\mathrm{PDH}$ nanoparticles $(1 \mathrm{mg} / \mathrm{mL})$ were mixed with $\mathrm{Ca}^{2+}$-containing solutions (final concentration: $600 \mathrm{mg} / \mathrm{mL}$ ) for different time points (10 $\mathrm{min}, 30 \mathrm{~min}, 120 \mathrm{~min}$, and $480 \mathrm{~min}$ ). Then, the nanoparticles chelating $\mathrm{Ca}^{2+}$ were obtained by centrifugation $(11,000 \mathrm{rpm}$, $10 \mathrm{~min}$ ), and the zeta potential was further measured. Meanwhile, the content of calcium ions was digested with aqua regia overnight and was then detected by inductively coupled plasma massspectrometry (ICP-MS, Thermo Fisher, Waltham, MA, USA).

\subsection{Biocompatibility}

Human umbilical vein endothelial cells (HUVECs, Shanghai Gefan Biotechnology Co., Ltd., P6, Shanghai, China) at the density of $1 \times 10^{4}$ cells/well were seeded into 96well plates and were incubated overnight at $37^{\circ} \mathrm{C}$ in a $5 \% \mathrm{CO}_{2}$ incubator. After $24 \mathrm{~h}$, a series of PDH nanoparticle concentrations were added to each well. After another $48 \mathrm{~h}$, 
MTT solution ( $5 \mathrm{mg} / \mathrm{mL}, 20 \mu \mathrm{L}$ ) was added. The culture continued for $4 \mathrm{~h}$. Then, the supernatant was discarded, and $150 \mu \mathrm{L}$ DMSO was added. The absorbance $(A)$ at $570 \mathrm{~nm}$ was determined by an M5 full-band multifunctional microplate reader (SynergyMx M5, Molecular Devices, San Francisco, CA, USA). Cell viability was calculated according to Formula (2):

$$
\text { Cell viability }(\%)=\frac{A_{\text {sample }}}{A_{\text {control }}} \times 100 \%
$$

\subsection{Cell Viability under Oxidative Conditions}

HUVECs $\left(1 \times 10^{4}\right.$ cells/well $)$ were seeded into 96-well plates and were incubated overnight. After $24 \mathrm{~h}$, cells were treated with $\mathrm{H}_{2} \mathrm{O}_{2}$ (the final concentration: $500 \mu \mathrm{M}$ ) and various concentrations of PDH nanoparticles. After another $48 \mathrm{~h}$, cell viability was detected by MTT, as described in Section 2.6.

\subsection{Annexin V-FITC and Propidium Iodide Staining}

HUVECs $\left(1 \times 10^{5}\right.$ cells/well) were seeded into 6-well plates and were incubated overnight. After $24 \mathrm{~h}$, the cells were treated with $\mathrm{H}_{2} \mathrm{O}_{2}$ (the final concentration: $500 \mu \mathrm{M}$ ) and PDH nanoparticles (the final concentration: $50 \mu \mathrm{g} / \mathrm{mL}$ ). After another $48 \mathrm{~h}$, the HUVECs were collected and were resuspended in the binding buffer provided by the annexin V-FITC apoptosis detection kit (Beyotime Biotechnology Co. Ltd., Shanghai, China). Subsequently, annexin V-FITC $(5 \mu \mathrm{L})$ and propidium iodide $(10 \mu \mathrm{L})$ were added in turn. After incubation for 20 min (room temperature), the cells were examined using a flow cytometer (ACEA NovoCyteTM, ACEA Biosciences, San Diego, CA, USA).

\subsection{Living Cells Staining}

HUVECs $\left(1 \times 10^{5}\right.$ cells / well $)$ were seeded into 6-well plates. After attachment, the cells were treated with $\mathrm{H}_{2} \mathrm{O}_{2}$ (the final concentration: $500 \mu \mathrm{M}$ ) and PDH nanoparticles (the final concentration: $50 \mu \mathrm{g} / \mathrm{mL}$ ) After another $48 \mathrm{~h}$, the culture medium was removed. Cells were washed with PBS three times. Then, calcein AM (the final concentration: $10 \mu \mathrm{M}$ )containing medium was replaced, and the cells were incubated for $30 \mathrm{~min}$. Then, the alive cells were immediately visualized under a fluorescence inverted microscope.

\subsection{ROS Levels in HUVECs}

The ROS levels in the HUVECs were detected according to a previous report [21]. HUVECs $\left(1 \times 10^{5}\right.$ cells / well $)$ were seeded into 6-well plates and were incubated overnight. Then, cells were treated with PDH nanoparticles (final concentration: $50 \mu \mathrm{g} / \mathrm{mL}$ ) before adding $\mathrm{H}_{2} \mathrm{O}_{2}$ (the final concentration: $500 \mu \mathrm{M}$ ). After 30 minutes of exposure to $\mathrm{H}_{2} \mathrm{O}_{2}$, the culture medium was discarded and was replaced with 2,7-dichlorodihydrofluorescein diacetate (DCFH-DA, the final concentration: $10 \mu \mathrm{M}$ )-containing medium. After incubation for $20 \mathrm{~min}$, the cells were washed with PBS several times and were imaged by a fluorescence inverted microscope (Axio Observer A1, Zeiss, Oberkochen, Germany).

\subsection{Calcium Content in HUVECs}

HUVECs $\left(1 \times 10^{5}\right.$ cells/well $)$ were seeded into 6-well plates and incubated overnight. Then, the cells were treated with $\mathrm{H}_{2} \mathrm{O}_{2}$ (the final concentration: $500 \mu \mathrm{M}$ ) and PDH nanoparticles (the final concentration: $50 \mu \mathrm{g} / \mathrm{mL}$ ). After another $48 \mathrm{~h}$, the culture medium was removed. Cells was washed with PBS three times. Fluo-4 AM (the final concentration: $5 \mu \mathrm{M}$ )-containing medium was added to the wells, and the cells were incubated for $30 \mathrm{~min}$. Then, the cells were washed with PBS several times and were imaged by a fluorescence inverted microscope (Axio Observer A1, Zeiss, Oberkochen, Germany).

\subsection{Western Blot}

HUVECs $\left(1 \times 10^{5}\right.$ cells/well $)$ were seeded into 6-well plates and were incubated overnight. Then, cells were treated with $\mathrm{H}_{2} \mathrm{O}_{2}$ (the final concentration: $500 \mu \mathrm{M}$ ) and PDH 
nanoparticles (the final concentration: $50 \mu \mathrm{g} / \mathrm{mL}$ ). After another $48 \mathrm{~h}$, HUVECs were lysed with RIPA lysis buffer (Beyotime Biotechnology Co. Ltd., Shanghai, China). The protein concentration was determined using a BCA protein assay kit (Beyotime Biotechnology Co. Ltd., Shanghai, China). The same amount of protein for each group was added to the SDS-PAGE electrophoresis gel $(8 \%)$. After electrophoresis, the membrane was probed overnight with GRP78 primary antibody $\left(1: 5000\right.$, abcam) at $4{ }^{\circ} \mathrm{C}$. After the washing process, the membrane was incubated with secondary antibody (secondary ant rabbit IgG HRP; 1:1000) at room temperature for $2 \mathrm{~h}$. Chemiluminescence agent (BeyoECL Plus, Beyotime Biotechnology Co. Ltd., Shanghai, China) was used for imaging and quantification in the Bio-Rad system (ChemiDoc Touch imaging system, Bio-Rad, Hercules, CA, USA).

\subsection{Superoxide Dismutase (SOD) Activity}

HUVECs $\left(1 \times 10^{5}\right.$ cells/well) were seeded into 6-well plates and were incubated overnight. Then, cells were treated with $\mathrm{H}_{2} \mathrm{O}_{2}$ (final concentration: $500 \mu \mathrm{M}$ ) and PDH nanoparticles (final concentration: $50 \mu \mathrm{g} / \mathrm{mL}$ ). After another $48 \mathrm{~h}$, SOD activity in the HUVECs was evaluated using the total SOD activity test kit (Beyotime Biotechnology Co. Ltd., Shanghai, China).

\subsection{Preparation of Indocyanine Green (ICG)-Labeled PDH Nanoparticles}

PDH nanoparticles and ICG were weighed $(1: 1, w / w)$ and were then dissolved in ultrapure water. The ICG-PDH complexes were obtained after being stirred for $2 \mathrm{~h}$ and after centrifugation at $11,000 \mathrm{rpm}$ for $10 \mathrm{~min}$.

\subsection{Cellular Uptake}

HUVECs were seeded into 12-well plates and were classified into six groups: PBS + ICG-labeled PDH nanoparticle $(50 \mu \mathrm{g} / \mathrm{mL})$ for $2 \mathrm{~h} ; \mathrm{H}_{2} \mathrm{O}_{2}(500 \mu \mathrm{M})+$ ICG-labeled PDH nanoparticles $(50 \mu \mathrm{g} / \mathrm{mL})$ for $2 \mathrm{~h}$; PBS + ICG-labeled PDH nanoparticles $(50 \mu \mathrm{g} / \mathrm{mL})$ for $4 \mathrm{~h} ; \mathrm{H}_{2} \mathrm{O}_{2}(500 \mu \mathrm{M})+$ ICG-labeled PDH nanoparticles $(50 \mu \mathrm{g} / \mathrm{mL})$ for $4 \mathrm{~h}$; PBS + ICGlabeled PDH nanoparticle $(50 \mu \mathrm{g} / \mathrm{mL})$ for $6 \mathrm{~h}$; and $\mathrm{H}_{2} \mathrm{O}_{2}(500 \mu \mathrm{M})+$ ICG-labeled PDH nanoparticles $(50 \mu \mathrm{g} / \mathrm{mL})$ for $6 \mathrm{~h}$. After the washing process, the cells were collected and detected by flow cytometry (ACEA NovoCyteTM, ACEA Biosciences, San Diego, CA, USA, FL channel: APC-A750, numeber of events: $100 \mu \mathrm{L}$ ). HUVECs without any treatment were used as a control.

\subsection{Mechanism of Cellular Uptake}

Cells were seeded at $2 \times 10^{4}$ cells per well in a 48 -well plate. The cells were pretreated with a clathrin-mediated uptake inhibitor (Chlorpromazine, $25 \mu \mathrm{M}$ ), caveolin-mediated uptake inhibitor (indomethacin, $50 \mu \mathrm{M}$ ), macropinocytosis inhibitor (amiloride, $50 \mu \mathrm{M}$ ), and lipid raft-mediated uptake inhibitor $\left(\mathrm{M}-\beta-\mathrm{CD}, 10 \mu \mathrm{g} / \mathrm{mL}\right.$ ) for $30 \mathrm{~min}$. The $\mathrm{H}_{2} \mathrm{O}_{2}$ and ICG-PDH complexes were added, and cultures were incubated for another $4 \mathrm{~h}$. After the washing process, the cells were collected and detected by flow cytometry (ACEA NovoCyteTM, ACEA Biosciences, San Diego, CA, USA; FL channel: APC-A750, numeber of events: 10,000 cells).

\subsection{Lysosome-Tracking Experiments}

HUVECs were treated with $\mathrm{H}_{2} \mathrm{O}_{2}$ and ICG-labeled PDH nanoparticles for $4 \mathrm{~h}$. Lysosomes were dyed with LysoTracker (Beyotime Biotechnology Co. Ltd., Shanghai, China) at a concentration of $50 \mathrm{nM}$ for $30 \mathrm{~min}$. After being washed three times with PBS, the fluorescence in the cells was monitored using a laser confocal microscope (Olympus BX61, Olympus Ltd., Tokyo, Japan).

\subsection{Biodistribution}

The ALI model was established via the intratracheal instillation of a lipopolysaccharide solution (LPS, $2 \mathrm{mg} / \mathrm{kg}$ ) $[25,26]$. Once completed, the mice were quickly erected to promote 
the distribution of the instilled solution into the lung. The ALI model was established after stimulation for $6 \mathrm{~h}$. Mice were randomly distributed into two groups: the control (healthy mice) and the ALI model.

The control and ALI mice were intravenously injected with ICG-PDH nanoparticles at a dose of $10 \mathrm{mg} / \mathrm{kg}$. After $2 \mathrm{~h}, 12 \mathrm{~h}, 24 \mathrm{~h}$, and $48 \mathrm{~h}$, mice were euthanized, and their organs were collected shortly after. The Maestro in vivo imaging system (Caliper, Hopkington, MA, USA) was used to measure the fluorescence signals in the mouse organs. The parameters were set at: filter $=$ ICG $790 \mathrm{~nm}$; exposure time $=1440 \mathrm{~ms}$.

\subsection{Acute Lung Injury Treatment}

Mice were randomly distributed into four groups: (1) healthy mice $(n=6)$; (2) ALI mice treated with PBS $(n=6)$; (3) ALI mice treated with methylprednisolone hemisuccinate $(n=6)$; and (4) ALI mice treated with PDH nanoparticles $(n=6)$. Methylprednisolone hemisuccinate is the primary drug in clinical ALI treatment, so it was used as the positive control in this study.

A total of $48 \mathrm{~h}$ after administration, the mice were sacrificed, and their lungs were collected and weighed.

The organs (heart, liver, spleen, lung, and kidneys) were collected and were fixed with $4 \%$ paraformaldehyde for $48 \mathrm{~h}$. Then, the embedded organs were cut with a microtome to prepare 5 - $\mu$ m-thick sections and were dried for HE staining.

After sacrifice, the mice were fixed in the supine position. Bronchoalveolar lavage fluid (BALF) was obtained. The collected BALF was quickly centrifuged at $1300 \mathrm{rpm}$ for $10 \mathrm{~min}$, and the supernatant was harvested and stored at $-80^{\circ} \mathrm{C}$ until use.

The precipitate was then lysed using the red blood cell lysis buffer (Beyotime Biotechnology Co. Ltd., Shanghai, China) for $1 \mathrm{~min}$. Thereafter, $7 \mathrm{~mL}$ PBS was added to stop the lysis process. Then, the mixture was centrifuged at $1300 \mathrm{rpm}$ for $10 \mathrm{~min}$. The obtained precipitate was further mixed with $500 \mu \mathrm{L}$ of PBS to form a cell suspension, and $50 \mu \mathrm{L}$ of this cell suspension was used to analyze the total cell counts using a hemocytometer. The remaining cells were treated with PE-labeled rat anti-mouse Ly-6G/Ly-6C monoclonal antibody (Elabscience, Wuhan, China, 50 tests) and FITC-labeled rat anti-mouse CD11b monoclonal antibody (Elabscience, 50 tests) at $4{ }^{\circ} \mathrm{C}$ for $20 \mathrm{~min}$. Then, the cell samples were washed with PBS and were centrifuged at $1300 \mathrm{rpm}$ for $10 \mathrm{~min}$. The precipitate was resuspended and was evaluated by flow cytometry (FL channel: FITC, PE; number of events: 10,000 cells).

The collected lungs were cleaned and lysed. After centrifugation (13,000 rpm, $15 \mathrm{~min})$, the supernatant was harvested. The levels of TNF- $\alpha$ and IL- 6 in the supernatant were further measured by ELISA kits (Boster Biological Technology Co. Ltd., Wuhan, China).

\subsection{Statistical Analysis}

Comparative analysis of the differences between groups was calculated by one-way analysis of variance or t test with Prism 7.0 (95\% confidence interval, GraphPad Software, San Diego, CA, USA). A significant difference was set at ${ }^{* * *} p<0.001,{ }^{* *} p<0.01$, and ${ }^{*} p<0.05$. Values are displayed in the form of mean \pm standard deviation.

\section{Results}

\subsection{Characterization of PDH Nanoparticles}

In the process of preparing $\mathrm{PDH}$ nanoparticles, the oxidant content, water-oil ratio, and stirring speed are the key conditions that must be considered to control the particle size of nanoparticles. As displayed in Table 1, with the increase in the $\mathrm{NaIO}_{4}$ content, the particle size increased first and then decreased over time. In turn, the polydispersity index (PDI) of these prepared nanoparticles decreased gradually and then increased. A previous report [22,27] demonstrated that the 1,8-DHN monomer was first oxidized, forming several 1,8 -DHN free radicals. Subsequently, a suitable dimer was obtained through the coupling of these free radicals, including three main types of dimers $\left(2-2^{\prime}, 4-4^{\prime}\right.$ and $2-4^{\prime}$ dimer). These 
dimers further oxidized, oligomerized, and self-assembled through molecular hydrogen bonds to form spherical nanoparticles. In addition, a higher proportion of $\mathrm{NaIO}_{4}$ can generate higher molecular weight oligomers, which may affect the size distribution and PDI of nanoparticles. Regarding the stirring speed, it had a minimal effect on the particle size (at around $115 \mathrm{~nm}$ ), while the nanoparticles prepared at medium rotational speed had a lower PDI. In contrast to stirring speed, the water-oil ratio had a significant influence on the particle size of the nanoparticles, as reflected by the smaller particle size with the higher water-oil ratio. The solubility of the 1,8-DHN monomer in different water-oil ratios may induce different oxidation levels since the concentration of monomers in the reaction is different. Moreover, the results of the PDI demonstrate that the dispersion became larger with an increase in the water-oil ratio. Accordingly, a better condition to prepare more stable PDH nanoparticles could be set at: $5 \% \mathrm{NaIO}_{4}, 400 \mathrm{rpm}$, and 5\% acetonitrile. The particle size and PDI of the obtained nanoparticles were $126.17 \pm 10.21 \mathrm{~nm}$ and $0.039 \pm 0.049$, respectively.

Table 1. Size of polydispersity index of PDH nanoparticles.

\begin{tabular}{cccc}
\hline \multicolumn{2}{c}{ Parameters } & Size (nm) & Polydispersity Index (PDI) \\
\hline & 0.015 & $98.95 \pm 8.01$ & $0.210 \pm 0.042$ \\
$\mathrm{NaIO}_{4}(\%, w / v)$ & 0.03 & $148.04 \pm 0.00$ & $0.066 \pm 0.022$ \\
& 0.04 & $142.28 \pm 8.15$ & $0.071 \pm 0.058$ \\
& 0.05 & $126.17 \pm 10.21$ & $0.039 \pm 0.049$ \\
& 0.06 & $113.35 \pm 10.87$ & $0.098 \pm 0.073$ \\
\hline \multirow{3}{*}{ Speed(rpm) } & 200 & $107.30 \pm 8.68$ & $0.147 \pm 0.030$ \\
& 400 & $126.17 \pm 10.21$ & $0.039 \pm 0.049$ \\
& 600 & $116.36 \pm 9.42$ & $0.054 \pm 0.042$ \\
& 800 & $85.87 \pm 34.66$ & $0.247 \pm 0.083$ \\
Acetonitrile $(\%)$ & 1000 & $111.59 \pm 6.39$ & $0.171 \pm 0.083$ \\
& 2.5 & $126.17 \pm 10.21$ & - \\
& 5 & $119.37 \pm 5.66$ & $0.039 \pm 0.049$ \\
& 10 & $104.53 \pm 10.02$ & $0.128 \pm 0.013$ \\
& 20 & $9.32 \pm 4.83$ & $0.152 \pm 0.016$ \\
\hline
\end{tabular}

Figure 1 presents the characterization of the obtained PDH nanoparticles. As displayed, the PDH nanoparticles are shaped as spheres with a diameter of about $125 \mathrm{~nm}$ (Figure 1A). After storage for 1, 3, 8, 10, 15, and 17 days (room temperature), these nanoparticles did not significantly change over time in regard to their particle size and PDI (Figure 1B). Meanwhile, the zeta potential was also measured. It should be noted that the PDH nanoparticles showed non-significant changes in terms of zeta potential on days 1,8 , and 15 (Figure 1C). In the in vitro hemolysis assay, the hemolysis rate was $3.11 \pm 0.77 \%$ for PDH nanoparticles (Figure 1D). Considering that the hemolysis rate of the biomaterials is limited to 5\%, PDH-based micelles showed good blood compatibility. Moreover, dichlorodihydrofluorescein diacetate (DCFH) was used as a probe to detect the ROS scavenging activity of PDH nanoparticles toward $\mathrm{H}_{2} \mathrm{O}_{2}$. In the presence of $\mathrm{H}_{2} \mathrm{O}_{2}$, DCFH was oxidized and showed an absorbance peak at $488 \mathrm{~nm}$. Interestingly, it could be observed that the addition of PDH rapidly reduced the absorbance peak at $488 \mathrm{~nm}$ in the solution (Figure 1E). Following these observations, the ability to chelate calcium ions was further analyzed. With the incubation time extended, the zeta potential of PDH nanoparticles decreased (Figure 1G), implying an increasing calcium chelating capability. ICP-MS was employed to detect the calcium ion concentration in the nanoparticles. Notably, $45.66 \pm 5.69 \%$ of the calcium ions could be chelated in $4 \mathrm{~h}$. 

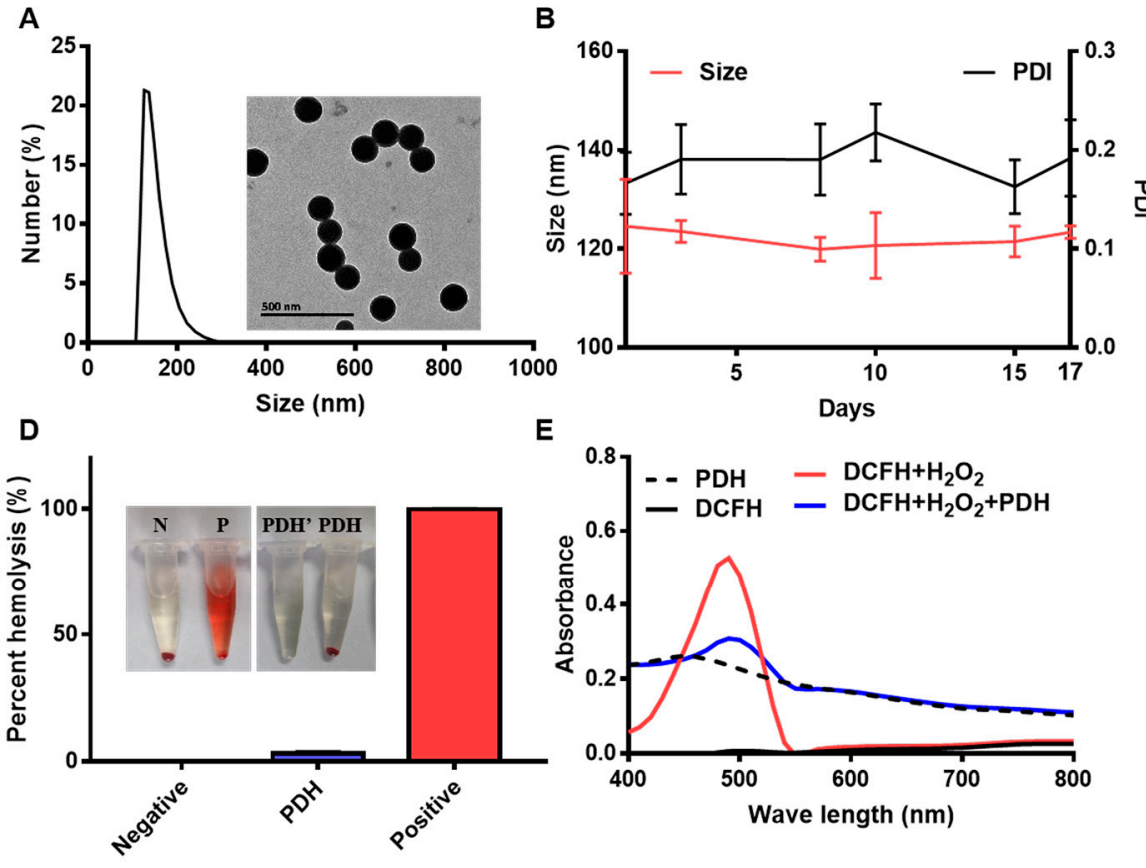

C
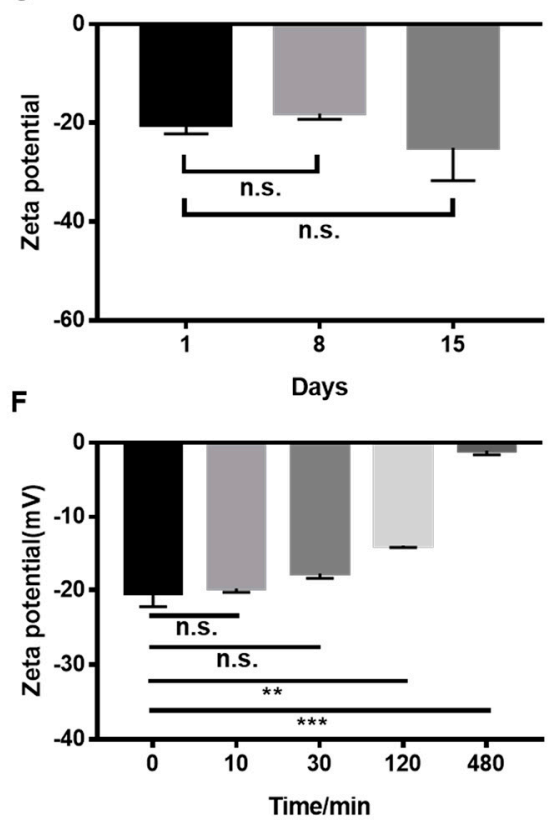

Figure 1. Characterization of PDH nanoparticles. (A) The size distribution and TEM images (inserted) of PDH nanoparticles. (B) Changes in nanoparticle size and polydispersity index after storage for 1, 3, 8, 10, 15, and 17 days. (C) Changes in zeta potential after storage for 1,8, and 15 days. (D) The hemolysis rate and images (inserted) of red blood cells after incubation with different nanoparticles. N: negative control, P: positive control, $\mathrm{PDH}^{\prime}$ : PDH sample mixed with saline, PDH: PDH sample mixed with red blood cells. (E) The absorbance of $\mathrm{PDH}, \mathrm{DCFH}$, DCFH $+\mathrm{H}_{2} \mathrm{O}_{2}$, and DCFH $+\mathrm{H}_{2} \mathrm{O}_{2}+\mathrm{PDH}_{\text {under }}$ different wavelengths. (F) Changes in zeta potential of $\mathrm{PDH}$ nanoparticles after incubation with calcium ion-containing solution (calcium chloride aqueous solution). (Results are presented as mean $\pm \mathrm{SD}$, n.s. is non-significant, ${ }^{* *} p<0.01$, *** $p<0.001, n=3)$.

\subsection{In Vitro Antioxidant Effect of PDH Nanoparticles}

Figure 2 shows the in vitro antioxidant effect of PDH nanoparticles. First, the MTT assay was applied to test the number of metabolic cells in the culture. The effect of PDH nanoparticles on cytotoxicity was investigated in normal HUVECs. The results demonstrated that even when the PDH concentration was as high as $1000 \mu \mathrm{g} / \mathrm{mL}$, cell viability was still more than $90 \%$ (Figure $2 \mathrm{~A}$ ), indicating that the melanin-like nanoparticles had good biocompatibility. Then, $\mathrm{H}_{2} \mathrm{O}_{2}$ was used to stimulate HUVECs to establish an oxidative stress model. The effect of $\mathrm{PDH}$ nanoparticles on cell viability was evaluated under oxidative stress conditions. As shown, the cell viability decreased from $100 \%$ to $14.76 \%$ in the presence of $\mathrm{H}_{2} \mathrm{O}_{2}$ (Figure 2B). After PDH treatment, the cell viability gradually increased along with the nanoparticle concentrations. At the concentration of $100 \mu \mathrm{g} / \mathrm{mL}$, the cell viability reached 78.01\%. Although the MTT test could provide information on the number of metabolic cells, a limitation was that an independent increase in the MTT reduction might occur in the presence of an oxidative stress or when the cellular oxidoreductases responsible for MTT reduction are affected by nanoparticles. 

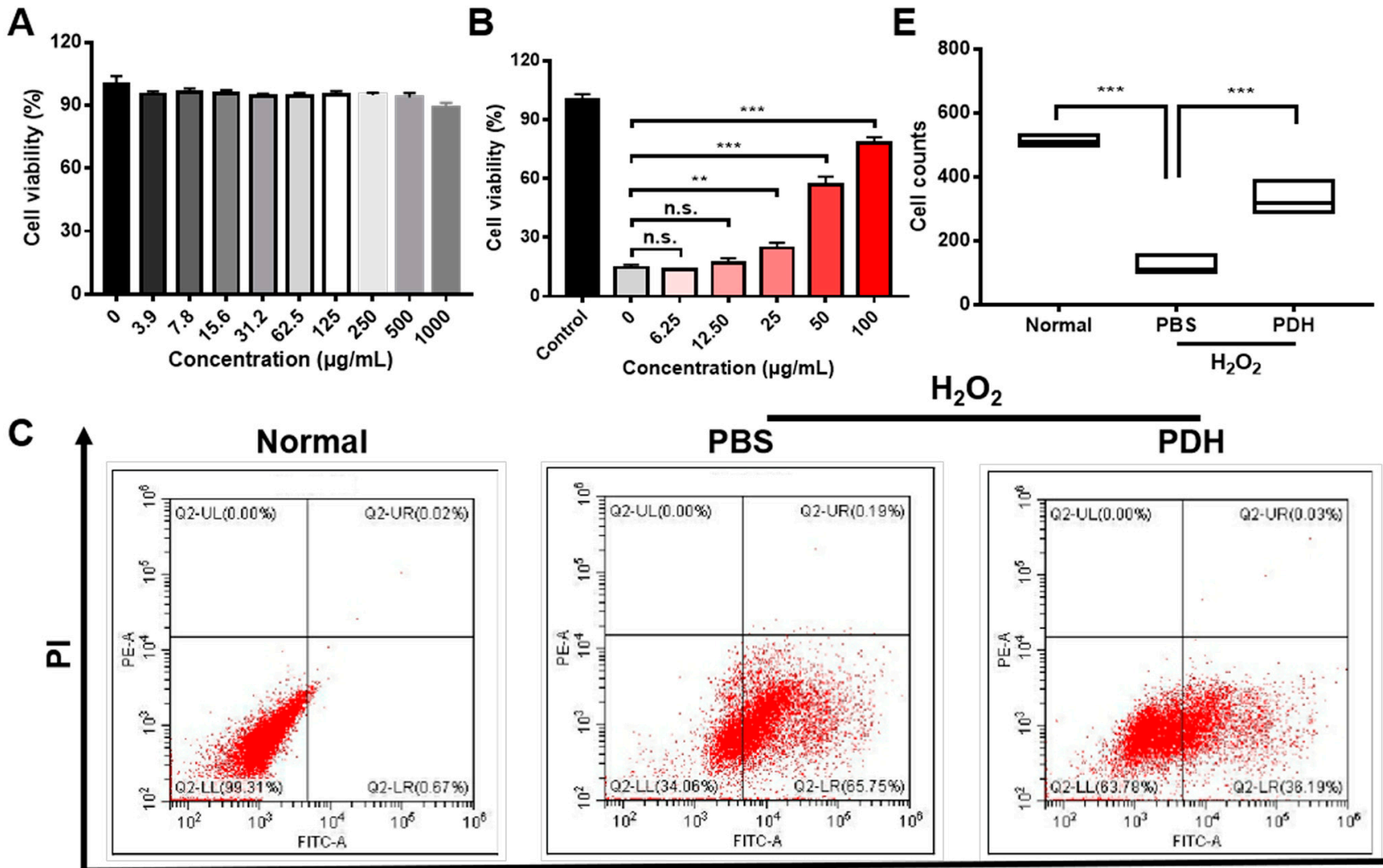

\section{$\mathrm{H}_{2} \mathrm{O}_{2}$}

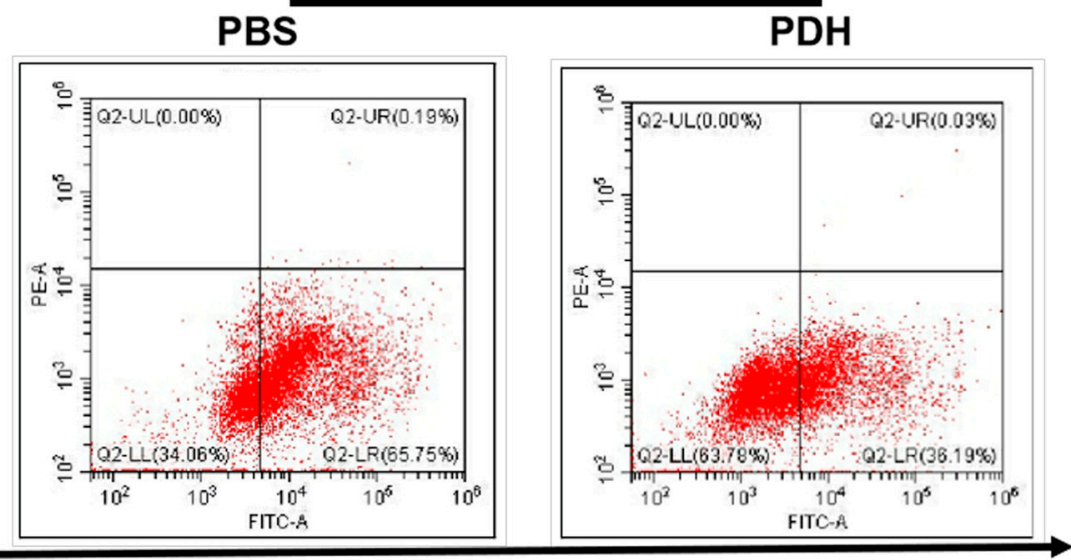

\section{Annexin-FITC $\quad \mathrm{H}_{2} \mathrm{O}_{2}$}
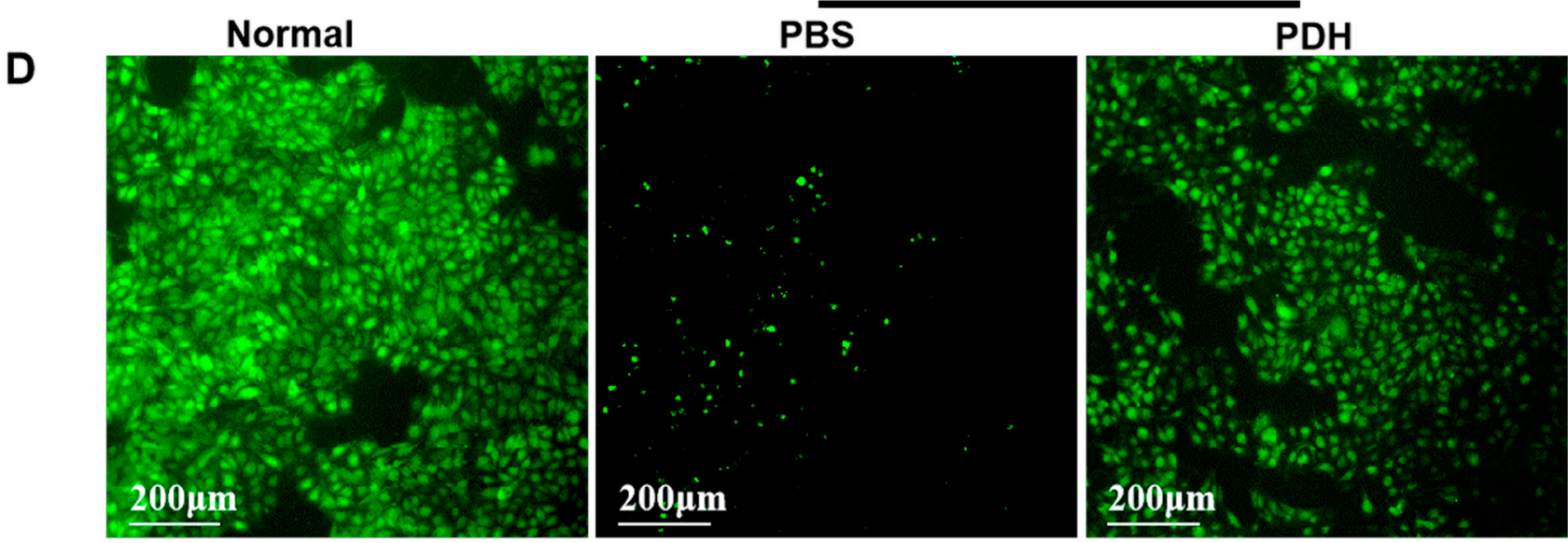

Figure 2. In vitro therapeutic effect of PDH nanoparticles. (A) The cell viability of PDH nanoparticles in normal HUVECs detected by MTT assay. (B) The cell viability after treatment with different concentrations of PDH nanoparticles detected by MTT assay. (C) The annexin-FITC and PI staining of HUVECs after different treatments evaluated by flow cytometry. The first quadrant indicates living cells. The second quadrant indicates early apoptotic cells. The third quadrant represents late apoptotic cells. The fourth quadrant shows the necrotic cells. (D) Living cells (labeled with calcein AM) after different treatment with PDH. (E) Cell count in Figure 2D measured by image J. (n.s. is non-significant, ${ }^{* *} p<0.01,{ }^{* * *} p<0.001, n=3$ ).

Since the early redistribution of phosphatidylserine is a general feature of apoptosis and since annexin-FITC could specifically combine with phosphatidylserine, annexin-FITC and propidium iodide (PI) staining was further used to monitor the number of apoptotic cells. The anti-apoptotic effect of PDH nanoparticles was detected by annexin-FITC and PI staining via flow cytometry. As displayed, the proportion of apoptotic cells significantly increased (from $0.67 \%$ to $65.75 \%$, Figure 2C). After PDH treatment, the proportion reduced to $36.19 \%$ (Figure $2 \mathrm{C}$ ). 
Calcein acetoxymethyl ester (calcein AM) is a fluorescent indicator that can provide information on the oxidative status of cells. It is hydrolyzed by living cells to produce calcein, which can emit strong green fluorescence. This allowed the effect of the PDH nanoparticles on the number of living cells to be investigated under oxidative stress conditions. As displayed, there are few fluorescent cells in the visual field of the PBStreated group, indicating few living cells (Figure 2D). In contrast, the PDH-treated group demonstrated a significant increase in fluorescent cells, implying that more HUVECs survived after $\mathrm{PDH}$ treatment under $\mathrm{H}_{2} \mathrm{O}_{2}$-induced oxidative stress compared to the PBS group (123 versus 332, Figure 2E). During the probe loading process, cells should be washed completely to avoid the influence of serum, oxidative stress, and nanoparticles, but as a result of this, newborn cells or cells without attachment may be removed.

Figure 3 exhibits the antioxidant mechanism of the PDH nanoparticles. The compound 2,7-Dichlorodihydrofluorescein diacetate (DCFH-DA) is a general fluorescent probe of oxidative stress. It can be hydrolyzed by cellular esterase to produce $2^{\prime}, 7^{\prime}$-dichlorodihydrofluorescein $(\mathrm{DCFH})$, and it can then be rapidly oxidized to produce a strong fluorescent product $2^{\prime}, 7^{\prime}$ dichlorofluorescein (DCF). Accordingly, the effect of PDH nanoparticles $(50 \mu \mathrm{g} / \mathrm{mL})$ on intracellular ROS levels was monitored. As shown in Figure 3A, a large quantity of fluorescent cells was observed in the PBS-treated group, revealing overproduced cellular ROS. PDH nanoparticles significantly reduced the fluorescent counts compared to the PBS group, implying that more ROS were scavenged. Considering that ROS had a short lifespan and were not easy to detect, the cells were first exposed to the PDH nanoparticles with the aim of internalization into cells. Reduced fluorescent ROS signals implied that the PDH nanoparticles effectively scavenged the intracellular ROS, hence protecting the endothelial cells against enhanced oxidative stress.

The intracellular ROS levels was associated with the SOD activity. A total SOD assay kit was used to detect the enzyme activity. Thus, the effect of PDH treatment on SOD activity could be evaluated. As evidenced, a reduced SOD activity could be observed in the PDH group (1334.24 U/mL) when compared to the PBS group (1141.77 U/mL, Figure 3C).

Since mass calcium ion swimming to the cytoplasm may result in endoplasmic reticulum stress, the cellular concentration of free calcium ions was detected. The Fluo-4 AM is a fluorescent indicator of free calcium ions. Its fluorescence is very weak and does change when the calcium ion concentration increases. Once the cells enter, Fluo-4 AM can be hydrolyzed to form Fluo-4, which can be combined with calcium ions and can produce strong fluorescence. Hence, the effect of the PDH nanoparticles on the cellular concentration of calcium ions was investigated. Clearly, $\mathrm{H}_{2} \mathrm{O}_{2}$ stimulation induced strong green fluorescence, indicating abundant calcium ion release into cytoplasm. Interestingly, $\mathrm{PDH}$ treatment induced a significant decrease in the fluorescent signals related to calcium in comparison to the PBS group (Figure 3B). Since the PDH nanoparticles preferred to locate in the cytoplasm, this led to a strong chelating ability on the calcium ion overload.

Calcium ion overload was essentially involved in endoplasmic reticulum stress. GRP78 is a general indicator of endoplasmic reticulum stress. Thus, the effect of the $\mathrm{PDH}$ nanoparticles on the inhibition of the endoplasmic reticulum stress response was assessed via the expression of GRP78. As evidenced, the expression level of GRP78 was significantly upgraded after $\mathrm{H}_{2} \mathrm{O}_{2}$ stimulation (Figure 3D). In contrast, $\mathrm{PDH}$ treatment decreased the GRP78 expression level.

To determine the mechanism of the PDH nanoparticles in suppressing the oxidative and endoplasmic reticulum stress response, an ICG-labeled PDH nanoparticle was prepared first, and its cellular uptake was further conducted. Stronger fluorescence intensity indicates the high internalization of ICG-labeled PDH nanoparticles into cells. It can be observed that the cellular fluorescence intensity increased with the extension of the incubation time (Figure 3E). Moreover, the further internalization of the PDH nanoparticles into the cells was detected in the presence of $\mathrm{H}_{2} \mathrm{O}_{2}$. The involvement of $\mathrm{H}_{2} \mathrm{O}_{2}$ causes cell membrane permeability to be enhanced [28]; thus, the ICG-labeled PDH can easily infiltrate cells. 




Figure 3. In vitro therapeutic mechanism of PDH nanoparticles $(50 \mu \mathrm{g} / \mathrm{mL})$. (A) The ROS levels in cells after different treatments using the DCFH-DA probe. (B) The concentrations of free calcium ions in cells after different treatments detected with Fluo-4 AM probe. (C) The SOD activity in cells after different treatments was detected by total SOD assay kit with WST-8. Three circles in the figure mean three samples detected in the normal group. Three squares indicate three samples investigated in the PBS group. And three triangles represent three samples detected in the PDH group. (D) The expression levels of GRP78 in cells after different treatments were analyzed by Western blot. (E) The fluorescent intensities in cells treated with ICG-labeled PDH nanoparticles in the presence or absence of $\mathrm{H}_{2} \mathrm{O}_{2}$ for $1 \mathrm{~h}, 2 \mathrm{~h}$, and $4 \mathrm{~h}$ were measured by flow cytometry. (F) The fluorescent intensity at $4 \mathrm{~h}$ in cells pretreated with different internalization inhibitors was measured by flow cytometry. (G) The co-localization of the lysosome tracker and ICG-labeled PDH nanoparticles at $4 \mathrm{~h}$. (n.s. is non-significant, $\left.{ }^{* *} p<0.01,{ }^{* * *} p<0.001, n=3\right)$. 
To investigate how PDH nanoparticles enter cells, different inhibitors of the endocytic pathways were used. The results showed that caveolin-mediated endocytosis, micropinocytosis, and lipid raft-mediated uptake made an important contribution to the internalization of PDH nanoparticles because the uptake processes were inhibited with various inhibitors, such as indomethacin (inhibitor of caveolin-mediated endocytosis), amiloride (inhibitor of macrocytosis), and methyl- $\beta$-cyclodextrin (inhibitor of lipid raft-mediated endocytosis). The cellular fluorescent signals reduced dramatically compared to the control group (Figure 3F). Theoretically, caveolin-mediated endocytosis could form caveosomes to escape lysosomal capture, enabling the PDH nanoparticles to cross the internal organelle barrier and eventually reach the cytoplasm to chelate calcium ions and scavenge excessive ROS.

To further detect the ICG-labeled PDH nanoparticles located in the cytoplasm, the lysosome was tracked by a lysotracker. Green represents the lysosome, while white indicates ICG-labeled PDH nanoparticles. Thus, based on the co-location/separation of green and white, the distribution of ICG-labeled PDH nanoparticles could be demonstrated. It was found that a large number of PDH nanoparticles were co-localized with the lysosome, indicating more accumulation in the lysosome before $\mathrm{H}_{2} \mathrm{O}_{2}$ stimulation. On the contrary, $\mathrm{PDH}$ nanoparticles revealed less co-localization with the lysosome, suggesting that more $\mathrm{PDH}$ nanoparticles entered into the cytoplasm. Lysosomes are organelles with many kinds of hydrolases, which can degrade nanoparticles. Therefore, the distribution of PDH-ICG complexes in the cells was an essential step for functioning. Having more PDH nanoparticles distributed in the cytoplasm contributed to a better effect on scavenging ROS and chelating $\mathrm{Ca}^{2+}$.

\subsection{In Vivo Antioxidant Effect of PDH Nanoparticles}

To assess the biodistribution of PDH nanoparticles in vivo, ALI-induced or healthy mice were injected intravenously with ICG-labeled PDH nanoparticles. After administration for $2 \mathrm{~h}, 12 \mathrm{~h}, 24 \mathrm{~h}$, and $48 \mathrm{~h}$, the organs were harvested and imaged. As displayed in Figure $4 \mathrm{~A}$, the fluorescence signals increased in time and peaked at about $24 \mathrm{~h}$. In healthy mice, a strong fluorescence signal could be observed in the liver rather than in the kidneys. However, in ALI mice, the fluorescent intensity in the kidneys increased, followed by a decreased fluorescence signal in the liver. In addition, this fluorescent signal preserved at $48 \mathrm{~h}$ in the ALI mice, while in normal mice, the fluorescence quickly decreased.

The therapeutic efficacy of PDH nanoparticles was assessed in the ALI murine model. As shown in Figure 4B, the lung of PBS-treated mouse showed significant pathological changes, as reflected by alveolar wall thickening, even alveolar disappearance, and infiltration of various inflammatory cells. After treatment, histological improvement could be noticed (alveolar structure and inflammatory cell infiltration). Compared to the PBS group, PDH-treated mice showed significantly improved inflammatory cell infiltration and alveolar wall thickening. Since inflammatory cell infiltration may influence organ weight, the lung wet weight was analyzed. As shown in Figure 4C, the PBS-treated group had a higher lung wet weight than the normal group (0.112 g versus $0.073 \mathrm{~g})$. Nevertheless, the lung wet weight significantly decreased in the methylprednisolone $(0.074 \mathrm{~g})$ and PDH (0.086 g) groups. This higher lung weight may be associated with enhanced inflammatory cell infiltration. To validate these findings, the total cell number in the pulmonary interstitial fluid was measured. As shown in Figure 4D, the PBS group displayed a sharp increase in the total cell counts after LPS challenge at $48 \mathrm{~h}(280,687 / \mathrm{mL}$ versus $14,617 / \mathrm{mL})$. When the mice were injected with $\mathrm{PDH}$, the total cell counts showed a significant decrease $(120,627 / \mathrm{mL})$. Among all of the inflammatory cells, neutrophil cells exerted a crucial role in the inflammatory cascade in the process of ALI development. Thus, pulmonary inflammatory cell infiltration was further monitored via the specific identification of CD11b and Ly6G (FITC-CD11b+ and PE-Ly6G+). As displayed, the neutrophil cell number increased from $36.90 \%$ to $83.70 \%$ in the bronchoalveolar lavage fluid after LPS stimulation (Figure 4E). Nevertheless, both the methylprednisolone (51.00\%) and PDH group (49.00\%) inhibited neutrophil cell infiltration. Pro-inflammatory cytokines (such as TNF- $\alpha$ and IL-6) are an- 
other indicator that can be used to evaluate inflammatory cascades in the development of ALI. Therefore, the levels of TNF- $\alpha$ and IL-6 in the lung tissues were further detected by ELISA kits. The results showed that the PBS-treated mice secreted more TNF- $\alpha$ and IL-6 in the lungs compared to the normal group (TNF- $\alpha$ : $179 \mathrm{pg} / \mathrm{mg}$ pro versus $41 \mathrm{pg} / \mathrm{mg}$ pro, IL-6: $31 \mathrm{pg} / \mathrm{mg}$ pro versus $126 \mathrm{pg} / \mathrm{mg}$ pro). Notably, the PDH group significantly inhibited the secretion of inflammatory cytokines.
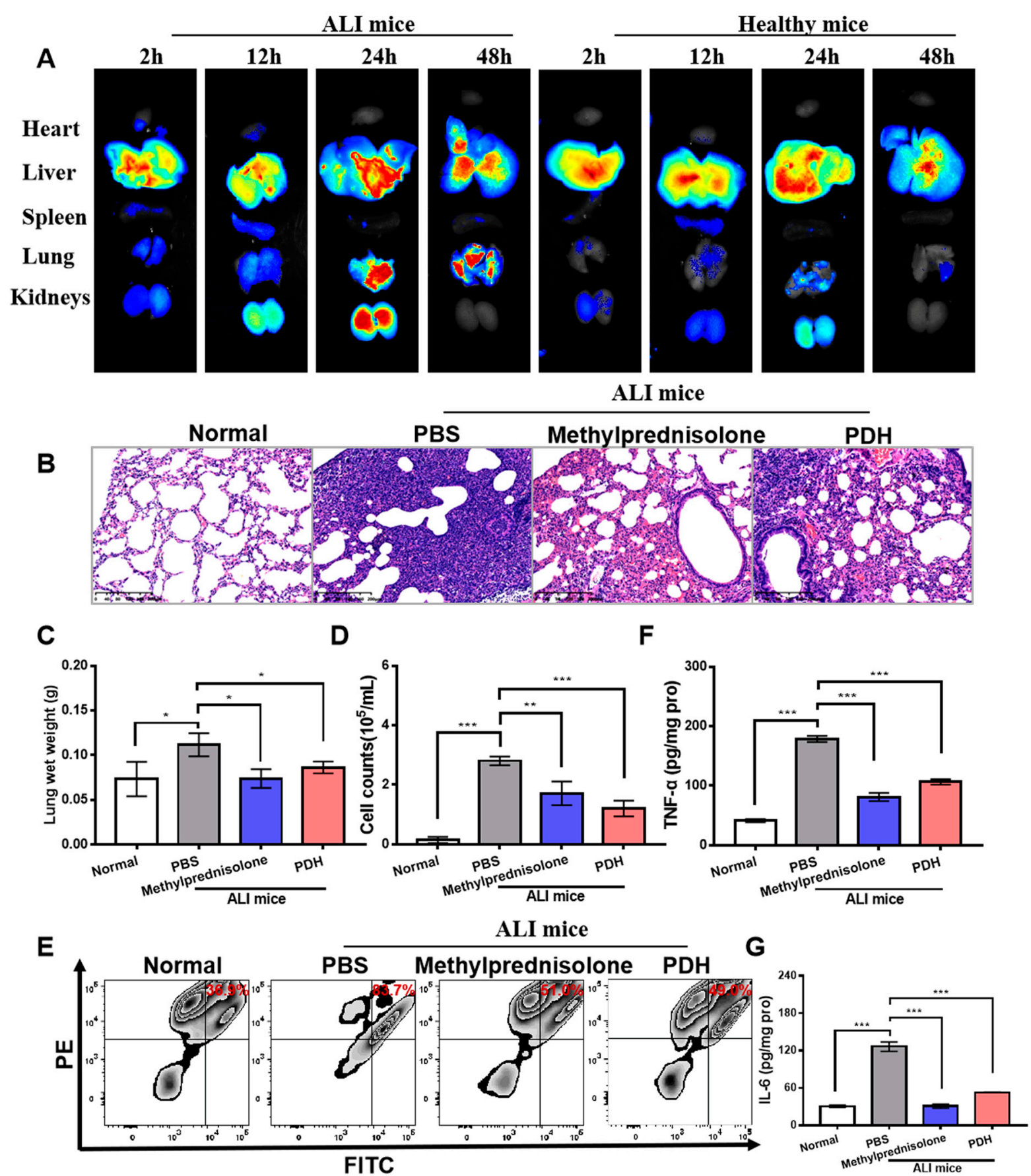

Figure 4. In vivo therapeutic effect of PDH nanoparticles on ALI-induced mice. (A) Biodistribution of PDH/ICG in vivo. The fluorescence images of harvested organs from mice treated with LPS or not at $2 \mathrm{~h}, 12 \mathrm{~h}, 24 \mathrm{~h}$ and $48 \mathrm{~h}$. (B) Morphologic alterations in lungs after different treatments were identified by hematoxylin and eosin staining. Scale bar $=200 \mu \mathrm{m}$. (C) The lung wet weight. (D) The total cell counts in the bronchoalveolar lavage fluid detected by flow cytometry. (E) The neutrophil counts in the bronchoalveolar lavage fluid measured by flow cytometry. (F) The level of TNF- $\alpha$ in lung tissues detected by TNF- $\alpha$ ELISA kit. (G) The level of IL-6 in lung tissues detected by IL-6 ELISA kit. $\left({ }^{*} p<0.05,{ }^{* *} p<0.01,{ }^{* * *} p<0.001, n=3\right)$. 


\subsection{Biosafety}

The adverse effect of PDH nanoparticles was evaluated by analyzing the counts of red blood cells, hemoglobin, and platelets. The results showed that PDH nanoparticles induced non-significant changes in the level of red blood cells (Figure 5A), hemoglobin (Figure 5B), and platelets (Figure 5C) compared to the untreated ALI mice or untreated normal mice. Moreover, H\&E staining revealed that $\mathrm{PDH}$ did not induce visible damage to the liver (Figure 5D), spleen (Figure 5E), kidneys (Figure 5F), or heart (Figure 5G), as reflected by the regular structure of myocardial fibers, spleen parenchyma, hepatic lobules, and renal tubules compared to the normal group. These results further confirm the biosafety of the prepared nanoparticles.


E


$\mathbf{F}$
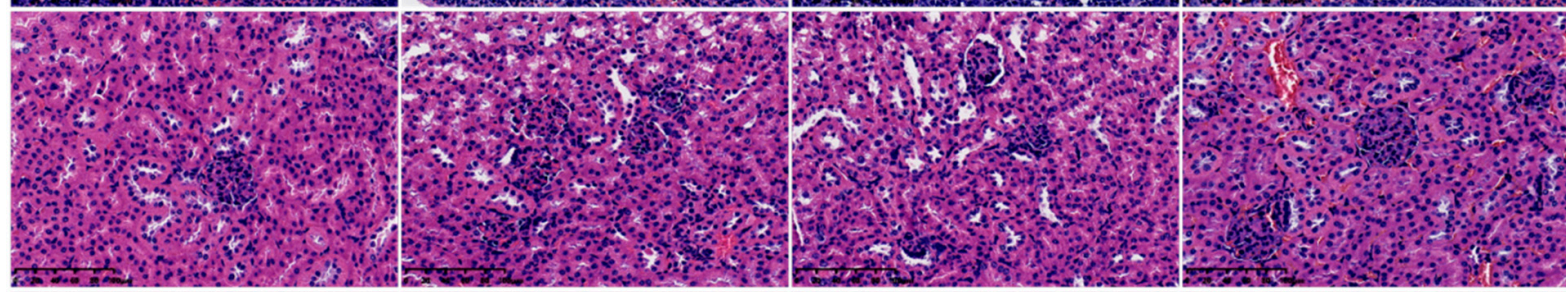

G

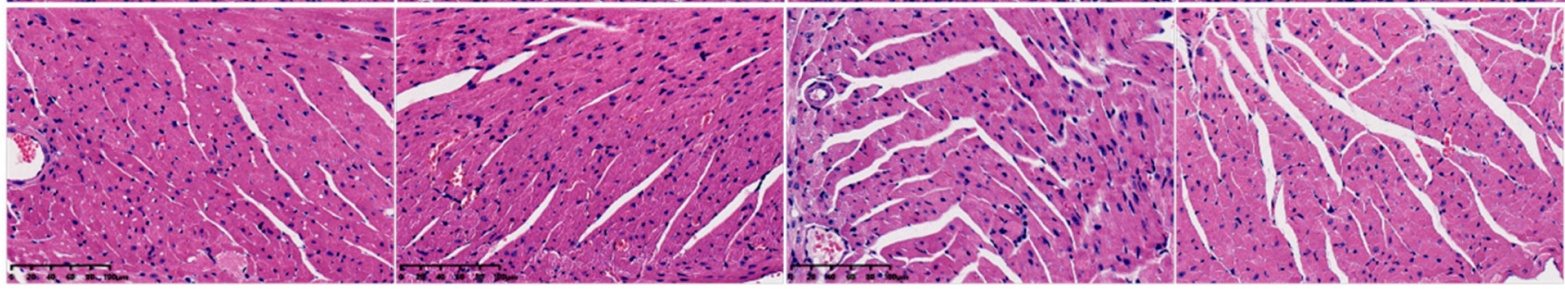

Figure 5. The biosafety of PDH nanoparticles in ALI mice. The changes in red blood cells (A), hemoglobin (B), and platelets $(C)$ detected by automatic blood analyzer (n.s. is non-significant, $n=6$ ). Representative images of liver $((\mathbf{D})$, scale bar $=200 \mu \mathrm{m})$, spleen $((\mathbf{E})$, scale bar $=100 \mu \mathrm{m})$, kidney $((\mathbf{F})$, scale bar $=100 \mu \mathrm{m})$, and heart $((\mathbf{G})$, scale bar $=100 \mu \mathrm{m})$ identified with hematoxylin and eosin staining. 


\section{Discussion and Conclusions}

Endoplasmic reticulum stress caused by calcium overload and excess ROS are considered to be two important pathological mechanisms of inflammatory response syndrome in ALI $[11,29,30]$. Melanin-like nanoenzymes are a series of macromolecules that contain phenolic hydroxyl and amino and imino acids in its structural units, which have been shown to have the functions of light protection [22], free radical capture [20], and photothermal conversion [31].

In the current study, 1,8-DHN were used as monomers to prepare melanin-like nanoenzymes. First, the preparation process was optimized by adjusting the concentration of oxidant, the stirring speed, and the water-oil ratio. After optimization, a nanoenzyme with a particle size of $126 \mathrm{~nm}$ was obtained. The prepared melanin-like nanoenzymes could be rapidly distributed to the injured lung at $2 \mathrm{~h}$ after LPS challenge, and the accumulation reached its maximum at $24 \mathrm{~h}$. Then, they entered the cytoplasm in large quantities through caveolin-mediated endocytosis. Once the nanoparticles were taken up by the cells, the nanoparticles chelated the overloaded calcium ions, contributing to an improvement in endoplasmic reticulum stress. At the same time, the excess ROS in the cytoplasm were removed, improving the ability of the cells to deal with oxidative stress and to inhibit the apoptosis of the injured endothelial cells. The in vivo antioxidant experiments at $48 \mathrm{~h}$ demonstrated that PDH could effectively decrease the infiltration of neutrophils in the ALI mice lung tissue and could significantly reduce the wet weight of the lung tissue and the secretion levels of inflammatory factors (TNF- $\alpha$ and IL-6). All of these improvements inhibited the pulmonary inflammatory response, thus preventing further injury.

The major strengths of the PDH nanoparticles for ALI can be summarized in four aspects: (i) PDH nanoparticles with a diameter of $126 \mathrm{~nm}$ exert functions that intrinsically inhibit the oxidative and endoplasmic reticulum stress response; (ii) the therapeutic mechanism is diverse, including scavenging ROS and chelating calcium ions; (iii) PHD nanoparticles demonstrate the potential to be nanocarriers, which suggests that they could be nanodrug delivery systems, providing an improved therapeutic effect; and (iv) the biosafety level is appropriate during treatment.

$\mathrm{PDH}$ nanoparticles have demonstrated many benefits and potential in ALI therapy. However, their use remains in the early stage and is still far from entering the clinical trial phase. We have yet to find solutions to considerable problems that challenge the therapeutic effect of these melanin-like nanoparticles:

(1) Biodistribution: Although a large quantity of PDH was accumulated in the injured lung and no obvious pathological changes were observed during treatment, the lung targeting efficiency remained unsatisfactory. An improvement in nanoparticles is necessary, and this can be achieved, for example, by choosing an appropriate particle size or by engineering the nanoparticle surface. A previous study [32] demonstrated that particle size significantly influenced the fate of nanoparticles, leading to different biodistribution and cellular uptake. However, there remains controversy regarding the notion that nanoparticles with a specific particle size may achieve maximum lung accumulation [33]. Hence, it is very important to investigate the lung aggregation of $\mathrm{PDH}$ nanoparticles with different particle sizes in inflammatory lungs. Moreover, some targeting moieties or membranes can be applied onto the surface of nanoparticles to circumvent the biologic obstacles, resulting in improved accumulation in lesions.

(2) Animal model: Previous experiments have showed that the tested drug always results in failure in clinical trials, although a good therapeutic effect in animal models has been demonstrated [33]. This indicates that the development of an accurate ALI model remains a challenge. Therefore, it is necessary to explore the complicated pathogenesis of ALI, followed by the establishment of an accurate ALI animal model for ALI treatment.

(3) Therapeutic mechanism: ALI is associated with hypoxia, bacterial/virus infections, endoplasmic reticulum stress, oxidative stress, inflammatory response, and so on. Moreover, many target cells are related to ALI, including neutrophils, macrophages, and endothelial cells. Due to these complex pathophysiological conditions induced by the het- 
erogeneity of etiological agents, a single drug or pathway for ALI therapy is not sufficient. In contrast, targeting different types of damaged cells or multiple pathways in the same cells simultaneously will significantly improve the therapeutic effect of ALI.

In summary, melanin-like nanoenzymes or melanin-like nanoenzyme-based drug delivery systems show great potential for clinical therapeutic perspectives. They represent the first drug delivery system that can both chelate $\mathrm{Ca}^{2+}$ overload and that can eliminate excess ROS, providing a novel strategy for the development of antioxidant nanomedicines. An appropriate particle size, engineered surface, accurate animal model, and coordinated therapy of multiple targets/pathways can improve the therapeutic effect, which may subsequently allow for gaps in both basic and clinical research to be filled. Considering that patients suffering from COVID-19 also show some symptoms similar to those of ALI, melanin-like nanoenzyme-relevant research may facilitate the identification of potential therapy options for COVID-19.

Author Contributions: X.-F.L.: manuscript editing and experimental studies; C.W.: experimental studies; J.-C.Z.: manuscript review; X.-L.X. and Y.-Z.D.: study concepts. All authors have read and agreed to the published version of the manuscript.

Funding: This research was funded by Natural Science Foundation of Zhejiang Province, grant number was LQ21H300008.

Institutional Review Board Statement: The study was conducted according to the guidelines of the National Institutes of Health (NIH, Bethesda, MD, USA), and approved by the Committee for Animal Experiments of Zhejiang University (12033, 26 February 2018).

Informed Consent Statement: Not applicable.

Data Availability Statement: Not applicable.

Acknowledgments: This work was supported by the Natural Science Foundation of Zhejiang Province (LQ21H300008).

Conflicts of Interest: All authors declare no financial/commercial conflict of interest.

\section{References}

1. Gouda, M.M.; Bhandary, Y.P. Acute Lung Injury: IL-17A-Mediated Inflammatory Pathway and Its Regulation by Curcumin. Inflammation 2019, 42, 1160-1169. [CrossRef]

2. Mowery, N.T.; Terzian, W.T.H.; Nelson, A.C. Acute Lung Injury. Curr. Prob. Surg. 2020, 57, 100777. [CrossRef] [PubMed]

3. Butt, Y.; Kurdowska, A.; Allen, T.C. Acute Lung Injury: A Clinical and Molecular Review. Arch. Pathol. Lab. Med. 2016, 140, 345-350. [CrossRef] [PubMed]

4. Chacko, B.; Peter, J.V.; Tharyan, P.; John, G.; Jeyaseelan, L. Pressure-controlled versus volume-controlled ventilation for acute respiratory failure due to acute lung injury (ALI) or acute respiratory distress syndrome (ARDS). Cochrane Database Syst. Rev. 2015, 1, CD008807. [CrossRef] [PubMed]

5. Kuldanek, S.A.; Kelher, M.; Silliman, C.C. Risk factors, management and prevention of transfusion-related acute lung injury: A comprehensive update. Expert Rev. Hematol. 2019, 12, 773-785. [CrossRef]

6. Kellner, M.; Noonepalle, S.; Lu, Q.; Srivastava, A.; Zemskov, E.; Black, S.M. ROS Signaling in the Pathogenesis of Acute Lung Injury (ALI) and Acute Respiratory Distress Syndrome (ARDS). In Pulmonary Vasculature Redox Signaling in Health and Disease; Springer: Cham, Switzerland, 2017; Volume 967, pp. 105-137.

7. Jiang, J.; Huang, K.; Xu, S.; Garcia, J.G.N.; Wang, C.; Cai, H. Targeting NOX4 Alleviates Sepsis-Induced Acute Lung Injury via Attenuation of Redox-Sensitive Activation of CaMKII/ERK1/2/MLCK and Endothelial Cell Barrier Dysfunction. Redox Biol. 2020, 36, 101638. [CrossRef] [PubMed]

8. Wei, K.; Luo, J.; Cao, J.; Peng, L.; Ren, L.; Zhang, F. Adiponectin Protects Obese Rats from Aggravated Acute Lung Injury via Suppression of Endoplasmic Reticulum Stress. Diabetes Metab. Syndr. Obes. Targets Ther. 2020, 13, 4179-4190. [CrossRef]

9. Huang, C.-Y.; Deng, J.-S.; Huang, W.-C.; Jiang, W.-P.; Huang, G.-J. Attenuation of Lipopolysaccharide-Induced Acute Lung Injury by Hispolon in Mice, Through Regulating the TLR4/PI3K/Akt/mTOR and Keap1/Nrf2/HO-1 Pathways, and Suppressing Oxidative Stress-Mediated ER Stress-Induced Apoptosis and Autophagy. Nutrients 2020, 12, 1742. [CrossRef]

10. Wang, L.; Ma, Q.; Chen, X.; Sha, H.; Ma, Z. Effects of resveratrol on calcium regulation in rats with severe acute pancreatitis. Eur. J. Pharmacol. 2008, 580, 271-276. [CrossRef]

11. Peng, Q.-Y.; Zou, Y.; Zhang, L.; Ai, M.-L.; Liu, W.; Ai, Y. Blocking Cyclic Adenosine Diphosphate Ribose-mediated Calcium Overload Attenuates Sepsis-induced Acute Lung Injury in Rats. Chin. Med. J. 2016, 129, 1725-1730. [CrossRef] 
12. Yang, H.; Lv, H.; Li, H.; Ci, X.; Peng, L. Oridonin Protects LPS-induced Acute Lung Injury by Modulating Nrf2-Mediated Oxidative Stress and Nrf2-Independent NLRP3 and NF-кB Pathways. Cell Commun. Signal. 2019, 17, 62. [CrossRef] [PubMed]

13. Li, T.; Wu, Y.N.; Wang, H.; Ma, J.Y.; Zhai, S.S.; Duan, J. Dapk1 Improves Inflammation, Oxidative Stress and Autophagy in LPS-Induced Acute Lung Injury via p38MAPK/NF-кB Signaling Pathway. Mol. Immunol. 2020, 120, 13-22. [CrossRef] [PubMed]

14. Lei, J.; Wei, Y.; Song, P.; Li, Y.; Zhang, T.; Feng, Q.; Xu, G. Cordycepin inhibits LPS-induced acute lung injury by inhibiting inflammation and oxidative stress. Eur. J. Pharmacol. 2018, 818, 110-114. [CrossRef] [PubMed]

15. Dehvari, K.; Chiu, S.-H.; Lin, J.-S.; Girma, W.M.; Ling, Y.-C.; Chang, J.-Y. Heteroatom doped carbon dots with nanoenzyme like properties as theranostic platforms for free radical scavenging, imaging, and chemotherapy. Acta Biomater. 2020, 114, 343-357. [CrossRef]

16. Feng, W.; Han, X.; Hu, H.; Chang, M.; Ding, L.; Xiang, H.; Chen, Y.; Li, Y. 2D vanadium carbide MXenzyme to alleviate ROS-mediated inflammatory and neurodegenerative diseases. Nat. Commun. 2021, 12, 1-16. [CrossRef]

17. He, W.; Wamer, W.; Xia, Q.; Yin, J.-J.; Fu, P.P. Enzyme-Like Activity of Nanomaterials. J. Environ. Sci. Health Part C 2014, 32, 186-211. [CrossRef]

18. Liu, Y.; Ai, K.; Lu, L. Polydopamine and Its Derivative Materials: Synthesis and Promising Applications in Energy, Environmental, and Biomedical Fields. Chem. Rev. 2014, 114, 5057-5115. [CrossRef] [PubMed]

19. Ding, F.; Gao, X.; Huang, X.; Ge, H.; Xie, M.; Qian, J.; Song, J.; Li, Y.; Zhu, X.; Zhang, C. Polydopamine-Coated Nucleic Acid Nanogel for siRNA-Mediated Low-Temperature Photothermal Therapy. Biomaterials 2020, 245, 119976. [CrossRef]

20. Bao, X.; Zhao, J.; Sun, J.; Hu, M.; Yang, X. Polydopamine Nanoparticles as Efficient Scavengers for Reactive Oxygen Species in Periodontal Disease. ACS Nano 2018, 12, 8882-8892. [CrossRef] [PubMed]

21. Zhao, H.; Zeng, Z.; Liu, L.; Chen, J.; Zhou, H.; Huang, L.; Huang, J.; Xu, H.; Xu, Y.; Chen, Z.; et al. Polydopamine nanoparticles for the treatment of acute inflammation-induced injury. Nanoscale 2018, 10, 6981-6991. [CrossRef]

22. Zhou, X.; McCallum, N.C.; Hu, Z.; Cao, W.; Gnanasekaran, K.; Feng, Y.; Stoddart, J.F.; Wang, Z.; Gianneschi, N.C. Artificial Allomelanin Nanoparticles. ACS Nano 2019, 13, 10980-10990. [CrossRef]

23. Xu, X.-L.; Li, W.-S.; Wang, X.-J.; Du, Y.-L.; Kang, X.-Q.; Hu, J.-B.; Li, S.-J.; Ying, X.-Y.; You, J.; Du, Y.-Z. Endogenous sialic acid-engineered micelles: A multifunctional platform for on-demand methotrexate delivery and bone repair of rheumatoid arthritis. Nanoscale 2018, 10, 2923-2935. [CrossRef]

24. Feng, L.; He, F.; Dai, Y.; Liu, B.; Yang, G.; Gai, S.; Niu, N.; Lv, R.; Li, C.; Yang, P. A Versatile Near Infrared Light Triggered Dual-Photosensitizer for Synchronous Bioimaging and Photodynamic Therapy. ACS Appl. Mater. Interfaces 2017, 9, 12993-13008. [CrossRef] [PubMed]

25. Li, S.-J.; Wang, X.-J.; Hu, J.-B.; Kang, X.-Q.; Chen, L.; Xu, X.-L.; Ying, X.-Y.; Jiang, S.-P.; Du, Y.-Z. Targeting delivery of simvastatin using ICAM-1 antibody-conjugated nanostructured lipid carriers for acute lung injury therapy. Drug Deliv. 2017, 24, 402-413. [CrossRef] [PubMed]

26. Jiang, S.; Li, S.; Hu, J.; Xu, X.; Wang, X.; Kang, X.; Qi, J.; Lu, X.; Wu, J.; Du, Y.; et al. Combined delivery of angiopoietin-1 gene and simvastatin mediated by anti-intercellular adhesion molecule-1 antibody-conjugated ternary nanoparticles for acute lung injury therapy. Nanomed. Nanotechnol. Biol. Med. 2019, 15, 25-36. [CrossRef]

27. McCallum, N.C.; Son, F.A.; Clemons, T.D.; Weigand, S.J.; Gnanasekaran, K.; Battistella, C.; Barnes, B.E.; Abeyratne-Perera, H.; Siwicka, Z.E.; Forman, C.J.; et al. Allomelanin: A Biopolymer of Intrinsic Microporosity. J. Am. Chem. Soc. 2021, 143, 4005-4016. [CrossRef]

28. Siflinger-Birnboim, A.; Malik, A.B. Regulation of endothelial permeability by second messengers. New Horiz. 1996, 4, 87-98.

29. Li, X.; Zhuang, X.; Qiao, T. Role of ferroptosis in the process of acute radiation-induced lung injury in mice. Biochem. Biophys. Res. Commun. 2019, 519, 240-245. [CrossRef] [PubMed]

30. Chen, X.; Wang, Y.; Xie, X.; Chen, H.; Zhu, Q.; Ge, Z.; Wei, H.; Deng, J.; Xia, Z.; Lian, Q. Heme Oxygenase-1 Reduces Sepsis-Induced Endoplasmic Reticulum Stress and Acute Lung Injury. Mediat. Inflamm. 2018, 2018, 1-10. [CrossRef]

31. Shu, G.; Chen, M.; Song, J.; Xu, X.; Lu, C.; Du, Y.; Xu, M.; Zhao, Z.; Zhu, M.; Fan, K.; et al. Sialic acid-engineered mesoporous polydopamine nanoparticles loaded with $\mathrm{SPIO}$ and $\mathrm{Fe}^{3+}$ as a novel theranostic agent for T1/T2 dual-mode MRI-guided combined chemo-photothermal treatment of hepatic cancer. Bioact. Mater. 2021, 6, 1423-1435. [CrossRef] [PubMed]

32. Jin, F.-Y.; Liu, D.; Yu, H.; Qi, J.; You, Y.; Xu, X.; Kang, X.; Wang, X.; Lu, K.; Ying, X.-Y.; et al. Sialic Acid-Functionalized PEG-PLGA Microspheres Loading Mitochondrial-Targeting-Modified Curcumin for Acute Lung Injury Therapy. Mol. Pharm. 2018, 16, 71-85. [CrossRef] [PubMed]

33. Qiao, Q.; Liu, X.; Yang, T.; Cui, K.; Kong, L.; Yang, C.; Zhang, Z. Nanomedicine for acute respiratory distress syndrome: The latest application, targeting strategy, and rational design. Acta Pharm. Sin. B 2021, 11, 3060-3091. [CrossRef] [PubMed] 